\title{
High strain rate deformation of porous sandstone and the asymmetry of earthquake damage in shallow fault zones
}

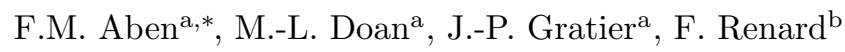 \\ ${ }^{a}$ University Grenoble Alpes, ISTerre, Grenoble, France \\ ${ }^{b}$ PGP, Department of Geosciences, University of Oslo, Oslo, Norway
}

\begin{abstract}
Observations of coseismic pulverization in porous sedimentary rocks in fault damage zones are scarce, in contrast to coseismic pulverization of crystalline rocks. Also, juxtaposition of stiff crystalline rocks and compliant porous rocks across a fault often yields an asymmetric damage zone geometry, with less damage in the more compliant side. In this study, we argue that such asymmetry near the sub-surface occurs because of a different response of lithology to similar transient loading conditions. Uniaxial unconfined high strain rate loadings with a split Hopkinson pressure bar were performed on dry and water saturated Rothbach sandstone core samples. Bedding anisotropy was taken into account by coring the samples parallel and perpendicular to the bedding. The results show that pervasive pulverization below the grain scale, such as observed in crystalline rock, does not occur in the sandstone samples for the explored strain rate range $\left(60-150 \mathrm{~s}^{-1}\right)$. Damage is mainly restricted to the scale of the grains, with intragranular deformation occurring only in weaker regions where compaction bands are formed. The presence of water and the bedding anisotropy mitigate the formation of compaction bands and motivates intergranular dilatation. The competition between inter- and intragranular damage during dynamic loading is explained with the geometric parameters of the rock in combination
\end{abstract}

\footnotetext{
* Corresponding author

Email address: franciscus.aben@univ-grenoble-alpes.fr (F.M. Aben)
}

Preprint submitted to Earth and Planetary Science Letters

December 6, 2016 
with two classic micromechanical models: the Hertzian contact model and the pore-emanated crack model. In conclusion, the observed microstructures can form in both quasi-static and dynamic loading regimes. Therefore caution is advised when interpreting the mechanism responsible for near-fault damage in sedimentary rock near the surface. Moreover, the results suggest that different responses of lithology to transient loading are responsible for sub-surface damage zone asymmetry.

Keywords: Fault zone damage, Coseismic damage, Rock

pulverization, High strain rate experiments, Sandstone compaction bands, Earthquake rupture mechanisms

1

2

\section{Introduction}

Intensively fractured rock or pulverized rock observed in fault damage zones are thought to be the product of transient coseismic loading and therefore have the potential to reveal past earthquake rupture conditions [1, 2, 3, 4, 5, 6]. These rocks are pervasively fractured down to the micron scale, but lack any shear or rotation of fragments [1, 7, 8]. The vast majority of pulverized rocks are observed in crystalline lithologies, often igneous, along crustal scale faults [2, 8, 6] and show intense pervasive damage, both inter- and intra-granular.

In contrast, there are very few observations on pulverization in sedimentary rock. Dolomites and limestones, sedimentary rocks that are crystalline in nature, were labeled pulverized in some studies $9,10,11$. For more porous sedimentary rocks, only a few observations exist [12, 13, of which the latter is related to a meteorite impact structure. Moreover, the interpretation as product of coseismic damage of these pulverized sedimentary rocks is ambiguous [6].

On a larger scale, pulverized crystalline rocks are often associated with an asymmetric distribution of sub-surface damage across a fault, where most damage is observed on the stiffer side consisting of crystalline rock [2, 8]. The juxtaposed more compliant side of the fault often consists of a less damaged sedimentary rock [2, 14]. Such asymmetric damage zone geometries have been 
linked to a bimaterial contrast at depth [2, 14, 8, and subsequently to a preferred rupture direction related to so-called Weertman pulses [15, 16, 17]. It is argued that such ruptures systematically produce more damage on the stiffer side of the fault, thereby explaining the lack of damage in the compliant lithology.

In this study, we propose another explanation of the discrepancy in damage between porous sedimentary rocks and crystalline rocks: the former respond differently to similar transient coseismic loadings than the latter. This response involves the deformation mechanisms that accommodate strain during transient loading conditions and the resulting microstructures. In the case of crystalline rocks, several laboratory studies have described the response to high strain rate loadings [18, 3, 19, 4, 20, 21]. However, to our knowledge, the high strain rate response of porous sedimentary rocks has not been studied yet in the Earth's science community, especially in terms of post-loading microstructures and deformation mechanisms.

Here, the mechanical and microstructural results are presented of uniaxial high strain rate loadings (strain rates between 60 and $150 \mathrm{~s}^{-1}$ ) performed on Rothbach sandstone samples with a Split Hopkinson Pressure Bar (SHPB) apparatus. The sedimentary bedding anisotropy in the rock allows for a study on the effect of pore and grain geometry on the mechanical behavior and microstructures, by loading bedding-parallel and bedding-perpendicular samples. Also, water saturated samples in these two orientations have been tested to identify the influence of fluids during coseismic loading in porous rocks.

Next, the observed differences between the four series of samples are discussed by using the geometric parameters of the rock in combination with classic micromechanical models for deformation in porous rocks. The most noteworthy microstructures induced by transient dynamic loading are compaction bands, which usually form at higher confining pressures and at low strain rate [22, 23]. The presented results suggest that the same microstructures form in both quasi-static and dynamic loading regimes. Therefore caution is advised when interpreting the mechanism responsible for near-fault damage in porous sedimentary rocks near the surface. Moreover, the results suggest that different 
responses of lithology to transient loading can explain sub-surface damage zone asymmetry.

\section{Material and methods}

\subsection{Sandstone samples}

Rothbach sandstone has a Lower Triassic age and is found in the Vosges region, France. The rock has been formed in a fluvial environment and contains cross-bedded laminations, causing a scatter in bedding orientations of $\sim 30^{\circ}$ (Figure 17). X-ray diffraction analyses from the sandstone block that was used for coring shows a mineralogical composition of $76.5 \%$ quartz, $13.4 \%$ feldspar (microcline), $3.4 \%$ mica, $5.9 \%$ clay minerals, of which $4.9 \%$ smectite, and less than $1 \%$ of various oxides. There is slightly less feldspar (-3\%) and more quartz $(8 \%)$ in the block compared to the mineral content of Rothbach sandstone in literature 24. The porosity, obtained on five samples by water imbibition, is $20.3 \pm 2.8 \%$, similar to the value of $19.9 \%$ porosity reported by [24.

Some alternation between coarser and finer grained beds is observed in thin sections of undeformed Rothbach sandstone, similar to the structure reported by 25. There is a higher abundance of feldspar in the finer grained beds. Image analysis reveals that the pores and grains are elongated, with the longest axis aligned along the bedding (Figure 1a, b). Pore diameters range between 25-270 $\mu \mathrm{m}$ with a mean of $90 \mu \mathrm{m}$ for the short axis and between 30-500 $\mu \mathrm{m}$ with a mean of $173 \mu \mathrm{m}$ for the long axis (Figure $1 \mathrm{k}$ ). The grain diameters are between 50 to $600 \mu \mathrm{m}$ with a mean of $240 \mu \mathrm{m}$ for the short axis and between 70 and $800 \mu \mathrm{m}$ with a mean of $330 \mu \mathrm{m}$ for the long axis (Figure 1 1F). These grain size values are similar to reported mean grain radii that vary between $110 \mu \mathrm{m}[26]$ to $140 \mu \mathrm{m}$ [27] and $152 \mu \mathrm{m}$ [24]. P-wave measurements by 28] reveal a beddingrelated anisotropy as well, with the faster velocities in the bedding-perpendicular direction. This effect increased when the pores were fluid-saturated 28]. The 
79

sedimentary anisotropy causes mechanical anisotropy as well, as shown by quasistatic deformation experiments by $[29,25]$.

All samples were cored from the same block and are $1.5 \mathrm{~cm}$ in diameter and length. The length/diameter ratio is close to 1 to reduce inertia effects during SHPB-loading tests [30]. Due to the laminations in the rock, the samples are technically oriented sub-perpendicular or sub-parallel to the bedding. In total, 16 perpendicular and 13 parallel samples were produced, labeled VS\# and VSX\#, respectively. Rectification ensured that the samples' top- and bottom surfaces were parallel within $80 \mu \mathrm{m}$ or less. Next, they were dried in an oven at $60^{\circ} \mathrm{C}$ for at least 48 hours. Two sets of samples (9 perpendicular, 7 parallel) were placed in a vacuum after which distilled water was added. They were kept submerged for more than 24 hours. The initial porosity reported earlier was calculated from the dry mass before imbibition, the mass after imbibition and the Archimedes mass (mass of the sample while suspended in water). 

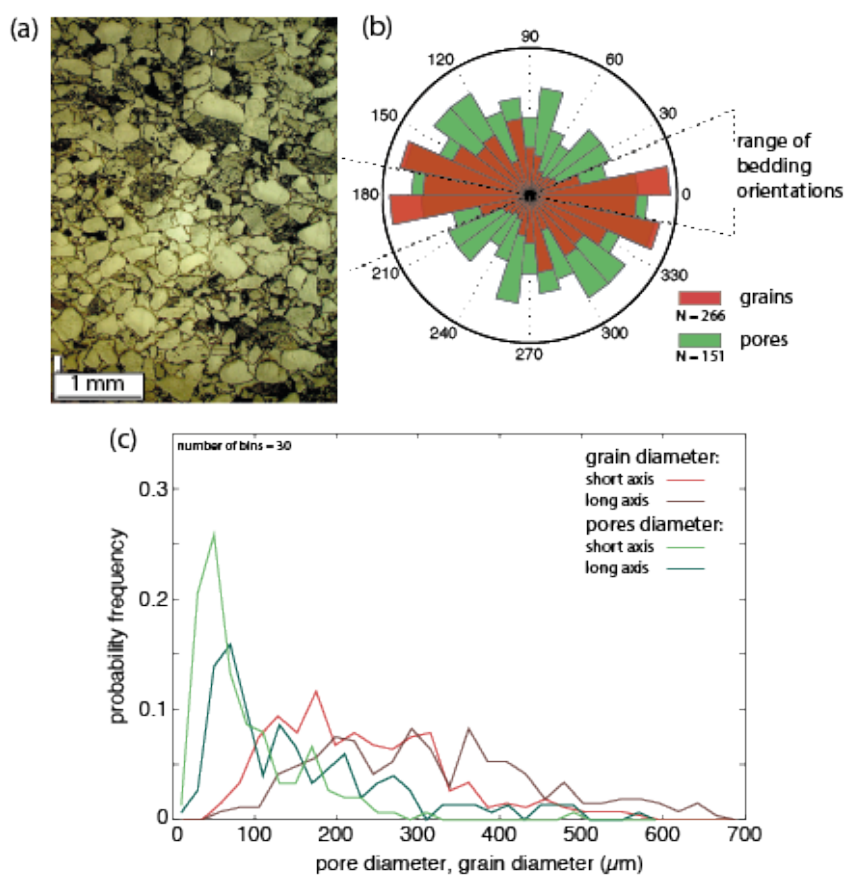

Figure 1: (a): Optical microscope image (incident light) of undeformed Rothbach sandstone. (b): The approximate range of orientations of the bedding planes in Rothbach sandstone. The orientation of the longest axis of the grains (red) show a clear anisotropic fabric related to the sedimentary bedding. The orientation of the longest axis of the pores (green) indicates heterogeneity in pore orientation related to the sedimentary bedding. Grain and pore orientations have been obtained by semi-automatic image analysis on thin sections. (c): The grain size (red curves) and pore size (green curves) distribution for the shortest and longest axes. For (b) and (c), $\mathrm{N}=266$ and $\mathrm{N}=151$ for grains and pores respectively. 


\subsection{Experimental setup}

Uniaxial high strain rate loading experiments were performed on a custom built "mini-Split Hopkinson Pressure Bar" (mini-SHPB) apparatus at the ISTerre laboratory in Grenoble described in [21]. It consists of steel in- and output- bars between which the sample is located and a steel striker (all are cylinders $2 \mathrm{~cm}$ in diameter). The striker is launched by a spring gun or compressed air gun towards the input bar end. The resulting planar stress wave subsequently travels the length of the input bar and loads the sample. During loading, part of the wave is reflected back and part is transmitted through the sample into the output bar. The stress waves are monitored by four strain gages, two on each bar. A 1D-wave analysis applied on the strain data results in the full stress-strain history of the sample. Further details on the SHPB apparatus and the data analysis are found in $31,32,21$.

The samples were mounted between the in- and output bars and attached to the bars by high vacuum grease. A minimum time interval between mounting and loading $(<60 \mathrm{~s})$ was pursued to prevent drainage of the water-saturated samples. Qualitatively, the amount of fluid that escaped from the samples was negligible.

It is essential to ensure a smooth rise of the stress wave in the earlier stages of loading to prevent stress disequilibrium issues. To do so, several types of pulse shapers have been used, depending on the strength of the sample. Nonetheless, it remained challenging to overcome stress disequilibrium problems at the onset of loading and a final conservative selection resulted in 13 loadings that were labeled reliable. The details on these loadings (3 dry and perpendicular, 3 saturated and perpendicular, 2 dry and parallel, 5 saturated and parallel) are listed in Table 1

After loading, some of the (partly) intact samples were impregnated with epoxy resin and processed for thin sections, either parallel or perpendicular to the loading direction. Microstructural observations were performed with an optical microscope equipped with a digital camera and by SEM. Several digital images were processed using the MatLab Image Analysis Toolbox. 


\begin{tabular}{|c|c|c|c|c|c|c|c|c|}
\hline 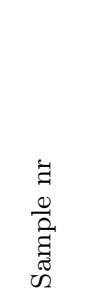 & & 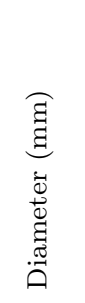 & 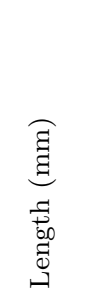 & 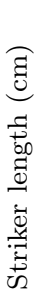 & Pulse shaper & 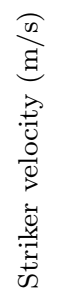 & 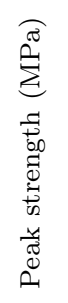 & 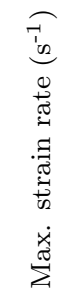 \\
\hline VS10 & saturated & 14.72 & 14.86 & 15 & lead & 4.57 & 33.0 & 119.5 \\
\hline VS11 & saturated & 14.70 & 14.92 & 15 & lead & 3.47 & 32.7 & 65.5 \\
\hline VS14 & saturated & 14.71 & 14.92 & 15 & composite lead, tin foil, cardboard & 6.70 & 38.2 & 95.6 \\
\hline VS15 & dry & 14.70 & 14.86 & 15 & lead & 4.62 & 45.9 & 110.2 \\
\hline VS16 & dry & 14.71 & 15.00 & 15 & lead & 3.27 & 39.3 & 71.9 \\
\hline VS6 & dry & 14.82 & 14.44 & 20 & cardboard & 2.87 & 49.6 & 152.1 \\
\hline VSX4 & dry & 14.45 & 15.06 & 10 & composite lead, tin foil, cardboard & 6.52 & 27.4 & 77.8 \\
\hline VSX7 & dry & 14.40 & 15.07 & 10 & composite lead, tin foil, cardboard & 6.75 & 28.7 & 78.5 \\
\hline VSX9 & saturated & 14.08 & 15.13 & 10 & composite lead, tin foil, cardboard & 4.96 & 23.9 & 59.1 \\
\hline VSX10 & saturated & 14.30 & 15.01 & 10 & composite lead, tin foil, cardboard & 4.07 & 26.2 & 75.2 \\
\hline VSX11 & saturated & 14.40 & 14.97 & 10 & composite lead, tin foil, cardboard & 6.55 & 22.8 & 80.9 \\
\hline VSX12 & saturated & 14.45 & 15.30 & 10 & composite lead, tin foil, cardboard & 8.55 & 30.4 & 131.6 \\
\hline VSX13 & saturated & 14.40 & 14.73 & 10 & composite lead, tin foil, cardboard & 5.99 & 26.5 & 76.8 \\
\hline
\end{tabular}

Table 1: Sample characteristics, experimental settings, peak strength, and maximum strain rate. 


\section{Results}

\subsection{Macroscopic damage}

The end-state of the samples is different for each set of loading conditions. For bedding-perpendicular loaded samples in dry conditions, the damage varied from intact to spalling-like surfaces parallel to the bedding (Figure 2 , orange frame). Also, there are suggestions of finer grained bands perpendicular to the loading direction. Their saturated counterparts remained intact or were reduced to a large amount of fragments (Figure 2a, pale blue frame). On those samples that remained intact, the fine-grained bands were not as pronounced as in the dry case.

The fine-grained bands and the spalling surfaces are not observed in the end-states of the bedding parallel loaded samples. Instead, both dry and saturated samples broke into several fragments with the fractures oriented parallel or at a low angle $\left(\sim 30^{\circ}\right)$ to the direction of loading (Figure 2 , red and dark blue frames). The size of the fragments decreased towards the grain size with increasing loading conditions, especially for saturated conditions (Figure 2 a, sample VSX12).

The spalling-like fracture surfaces mentioned above are mostly observed near the interface between the output bar and sample, and are typically created by tensile loading. The microstructures indicate that compression occurred before the formation of these tensile spalling surfaces; therefore it is suspected that this damage type is a post-loading artifact. They were formed as follows: when the transmitted stress pulse has completed one cycle along the length of the output bar, the bar moves away from the sample. Often, this movement results in direct detachment of the sample from the in- and output bars when loading crystalline rocks. However, in the case of sandstone it seems that penetration of the high vacuum grease into the abundantly available pores results in sufficient capillary force to prevent immediate detachment. This results in the buildup of tensile stress and failure along a weaker pre-damaged plane close to the output bar side. This is supported by the fact that only the most damaged samples 
show such features. As a consequence, the spalling microstructure is considered to be an artefact of the experimental procedure and will not be discussed later.

\subsection{Mechanical data}

The stress-strain curves of bedding-perpendicular loadings show a different mechanical behavior between dry and saturated loading conditions (Figure 2p). The dry samples achieve higher peak strength than saturated samples (Table 11. Also, these peak stresses are higher than the uniaxial compressive strength obtained at low strain rate, which is around $35 \mathrm{MPa}$ 33. Saturated samples accumulate more axial strain than dry samples and reach their peak strength at a higher axial strain. The elastic deformation interval yields a slightly lower slope for the saturated samples. For the dry samples, the deviation from the linear elastic part of the stress-strain curve is between 35 and $38 \mathrm{MPa}$. The saturated samples yield at lower stress, between 23 and $25 \mathrm{MPa}$.

All samples that are loaded bedding-parallel reach lower peak strengths relative to the bedding-perpendicular ones. The effect of fluid saturation is much less apparent on the bedding-parallel loaded samples. The peak strength of the dry samples is slightly higher than the saturated ones (Figure $2 \mathrm{p}$ and Table 1), and the saturated samples reach their peak strength at lower strain (Figure $2 \mathrm{p}$ ). The linear elastic interval is similar for dry and saturated samples and indicates a more compliant rock compared to dry bedding-perpendicular loaded samples. Yielding commences at low stresses (15-20 MPa).

The loading histories are slightly different from the classical loading curves obtained at high strain rate loading on crystalline rocks [18, 21]. High strain rate loadings on crystalline rock typically yield a strain rate history with one or two distinct peaks and a distinct 'hinge'-point after the first peak, where the first peak is related to elastic deformation, the 'hinge'-point to the start of dynamic fracturing and the second peak to catastrophic collapse of the sample [18, 21]. Here, such a clear distinction is harder to make since the elastic and inelastic contributions to the strain rate overlap. Using the approximate yielding point from the stress-strain curves (Figure 2b), the first strain rate peak related to 
(a)

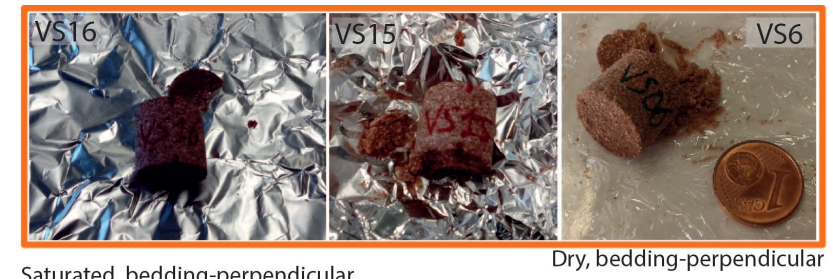

Saturated, bedding-perpendicular

Dry, bedding-perpendicular

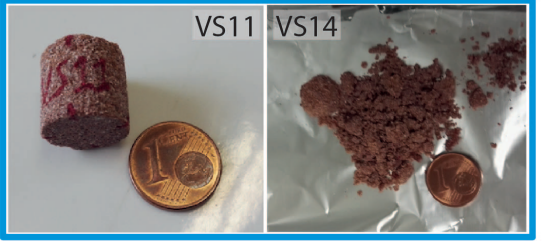

Saturated, bedding-parallel

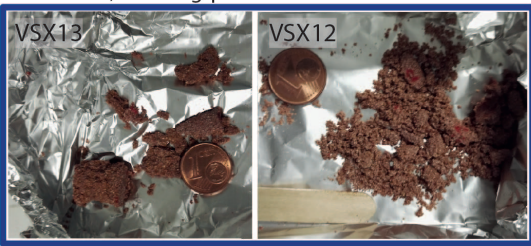

Dry, bedding-parallel

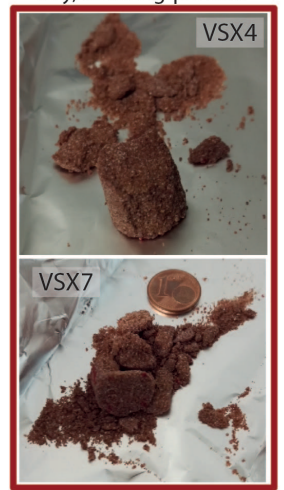

(b)

Stress - strain curves Rothbach sandstone

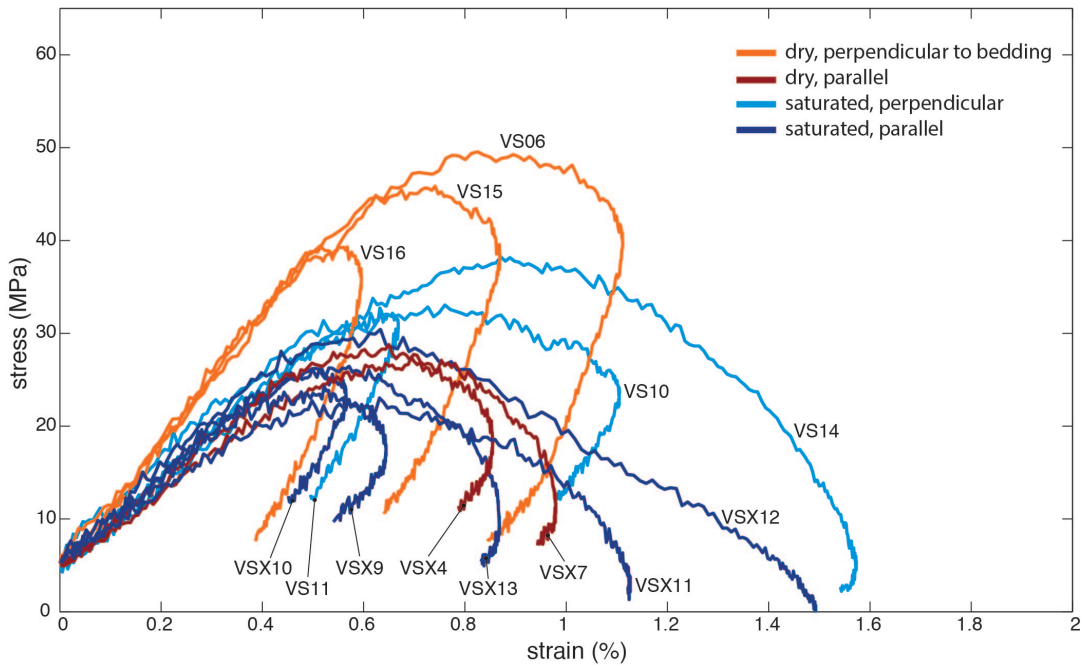

Figure 2: (a) Photographs of the post-mortem samples showing end-states that vary from intact to individual grains. The colored frames correspond to the colors used in (b) for the sample conditions. (b) The stress-strain curves for dynamic loading and damage of the 13 reliable samples. Color-coding indicates the sample conditions. The stress-strain curves have been cut off at $5 \mathrm{MPa}$ to facilitate direct comparison. 
elastic deformation can be recognized (Figure $3 \mathrm{a}$ ). After, rather than a yieldpoint there is a yield-interval up to a poorly defined second strain rate peak (Figure 3 a). This second strain rate peak is only recognized in the heavily fragmented samples (indicated in Figure $3 \mathrm{~b}$ ).

A weak dependence of the peak strength as function of peak strain rate is only recognized for the bedding-perpendicular dry loadings (Figure 3b). A clear strain rate threshold that separates the loadings with a second strain rate peak that result in heavily fragmented samples from the other samples in their respective series is not visible.

The full deformation history of the samples can be represented as the dissipated energy (the area bound by the stress-strain curve). The dissipated energy density is revealed by plotting the dissipated energy versus the residual axial strain (Figure 3c). The residual axial strain is the permanent strain after loading. Three linear trends become apparent: one for the dry and one for the saturated bedding-perpendicular series (57 and $30 \mathrm{MJ} / \mathrm{m}^{3}$, respectively), and one for the saturated bedding-perpendicular series $\left(19 \mathrm{MJ} / \mathrm{m}^{3}\right)$. The beddingparallel series contain too few samples over a too small range of dissipated energy and strain to define a clear trend. A lower slope means that less energy is dissipated for a similar amount of axial deformation. Thus, the presence of water makes the rock easier to deform and the rock is weaker when loaded parallel to the bedding instead of perpendicular to the bedding.

The approximate contours of the maximum strain rate are horizontal, except for sample VS14 that falls out of the general trend (Figure 35). This, in combination with the dissipated energy density, indicates that deformation in dry conditions depends more on strain rate than deformation in saturated conditions. 

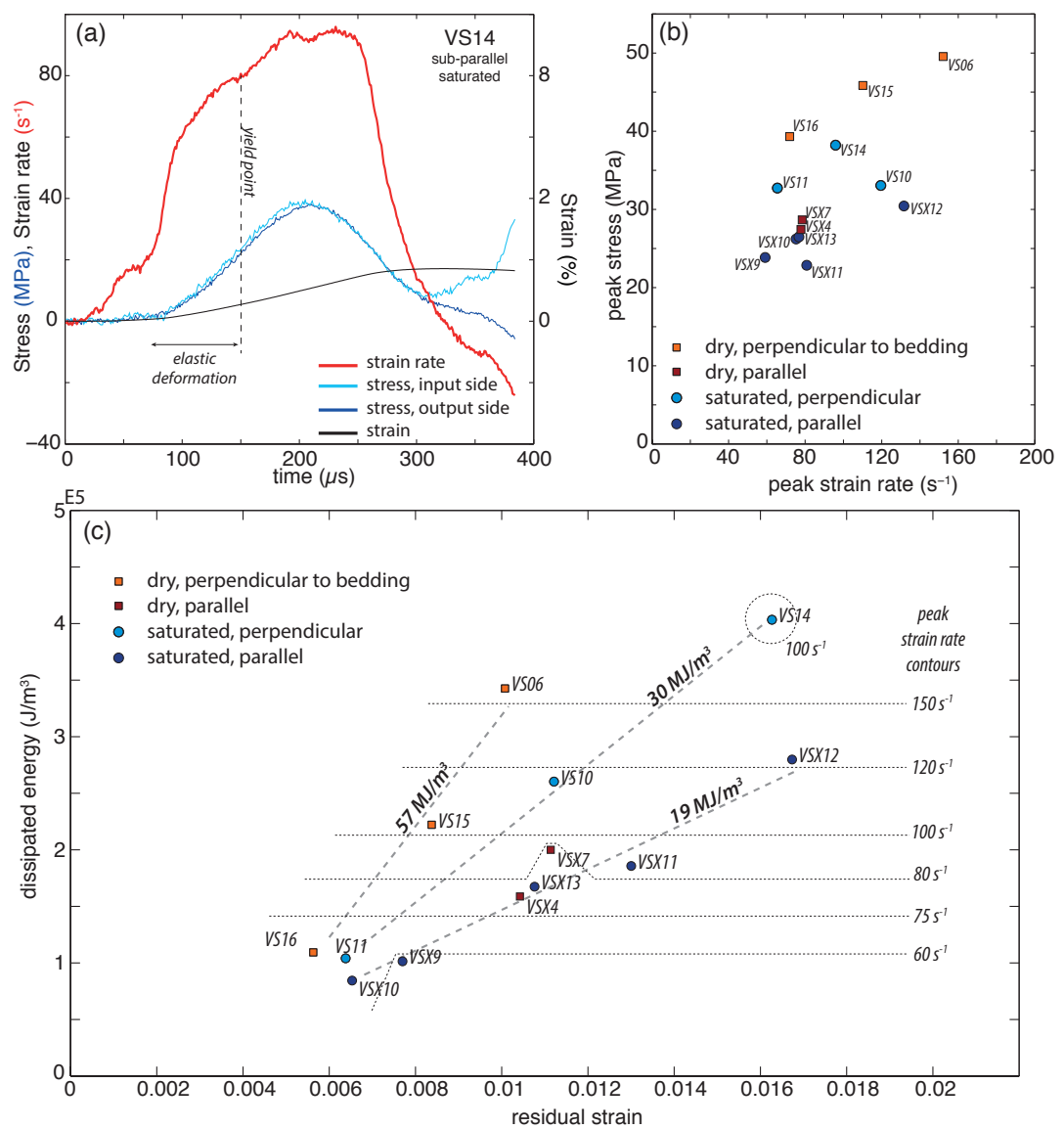

Figure 3: (a) Strain rate (red), stress (pale blue and dark blue) and strain (black) versus time for sample VS14. The pale blue stress curve is the stress at the input bar - sample interface, the blue for the output bar - sample interface. Both curves overlap, indicating good stress equilibrium. After $300 \mu \mathrm{s}$, incident and reflected waves overlap, resulting in artificial data. (b) The peak stress plotted versus the peak strain rate for all loadings. (c) Dissipated energy plotted versus the residual strain for all loadings. Strain rate contours indicate the approximate peak strain rates that were experienced by the sample. Slopes have been determined for three of the sample sets. 


\subsection{Microstructures}

For bedding-perpendicular loadings, darker colored bands are visible at the scale of the sample, which are not as evident in undamaged rock (Figure 4 ac). These bands are more pronounced in samples loaded under dry conditions than samples loaded under saturated conditions (Figure $4 \mathrm{p}$ ). The bands consist of finer grained material and are oriented sub-parallel with the sedimentary bedding. They do not always run over the whole diameter of the sample and their boundaries are somewhat diffuse (Figure $4 \mathrm{~b}$ ). A measure of the porosity for these bands is obtained by mapping the pore space on optical microscopy images taken parallel to the loading direction (for details, see Supplementary Material A). The surface occupied by pores in undeformed sandstone is $17.1 \%$. For the bedding-perpendicular dry loadings, the mean surface is reduced to $11.8 \%$, for the saturated samples it is slightly higher at $13.8 \%$. The pore space in these same samples determined from individual images outside the dark bands is higher, around $15-16 \%$. This reveals a strong reduction in pore space within these bands relative to the regions outside these bands and therefore they can be interpreted as compaction bands.

At higher magnification, the compaction bands contain a larger amount of feldspars, micas, and clays relative to the non-compacted regions (Figure 44). Grain crushing, especially of feldspar grains, has caused local pore collapse (Figure 4 and 5 a). Also, grains of micas show sign of intense deformation by folding (Figure 5a). This crushing of the grains and subsequent collapse of the pores and rearrangement of the grains causes the local compaction. The localization of compaction into bands is caused by the higher amounts of feldspar and micas in some sedimentary layers.

The grain size outside the compaction bands is generally larger and the matrix contains a higher amount of quartz grains. Some of these larger grains contain plenty of intra-granular fractures, while a large amount of the grains remain undamaged (Figure 5a). For dry loading conditions, these fractures are not often trans-granular, whereas for saturated conditions they are more often trans-granular and have been opened up. 
Inter-granular fracturing is difficult to distinguish in the thin sections, since rupturing in the cement is obscured by the chaotic structure of the cement itself. However, at some locations in bedding-parallel loaded samples, clear evidence of intergranular fracturing can be observed (Figure $5 \mathrm{p}$ ). Also, image analysis shows that the total pore space is $20.9 \%$, which is higher than the undamaged rock (see Supplementary Material A). Interestingly, some intragranular deformation is observed close to dilated pores (Figure $5 \mathrm{~b}$ ). These structures suggest that incidental intragranular fracturing has occurred before intergranular fracturing.

Dilatational intergranular deformation has not been observed in the beddingperpendicular loaded samples under dry conditions. Here, intergranular deformation caused by pore collapse can be inferred, but this is different in nature compared to the dilatational fracturing in the bedding-parallel loaded samples. For the saturated bedding-perpendicular loadings, intergranular dilatational deformation outside the compaction bands, in zones with larger grain sizes, did seem to have occurred, although in lesser degree compared to the beddingparallel loaded samples. 


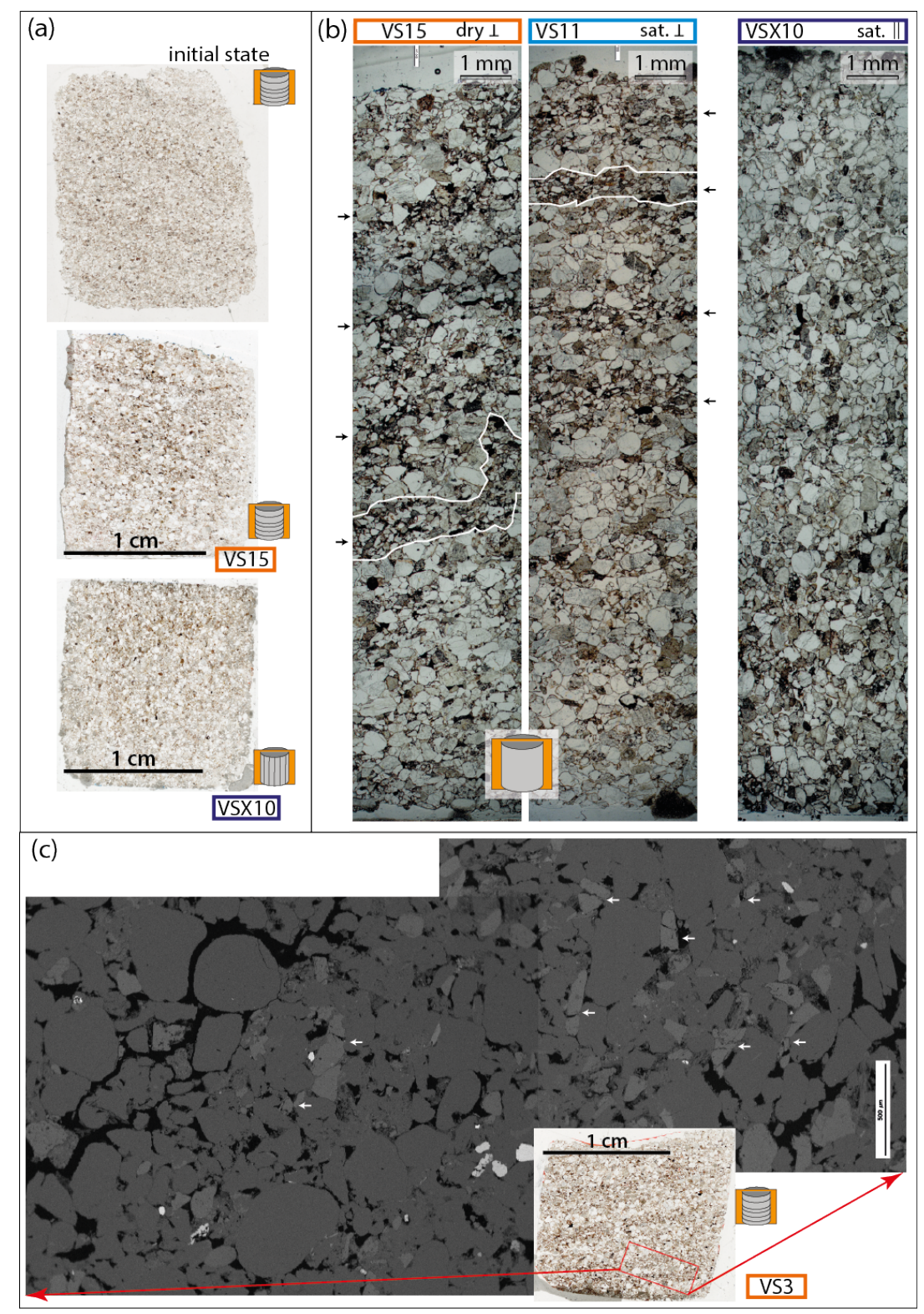


Figure 4: (a) Whole thin sections photographs of an undeformed Rothback sandstone sample (top), a dry bedding perpendicular loaded sample (bottom left) and a saturated bedding parallel loaded sample (bottom right). The bedding parallel loading sample shows dark compaction bands aligned with the sedimentary bedding. Note that there are no compaction bands (darker horizontal bands) visible in the initial sample and in the bedding-parallel loaded sample, only some alternation between finer and coarser grained material. (b) Photomicrograph compositions along the length of three samples that were loaded bedding perpendicular (left: dry conditions, middle: saturated conditions) and bedding parallel (right, saturated conditions). The bedding-perpendicular loaded samples show compaction bands (indicated by the black arrows. In each sample, one has been highlighted by a white rim). In contrast, the bedding-parallel loaded sample does not show compaction bands and contains more pores. (c) Overview image of compaction bands in sample VS3, where feldspar grains are often fractured (light gray grains, indicated by white arrows). Dark gray grains are mainly quartz grains, black areas is pore space. (Mechanical data of sample VS3 not included because of stress equilibrium issues). 

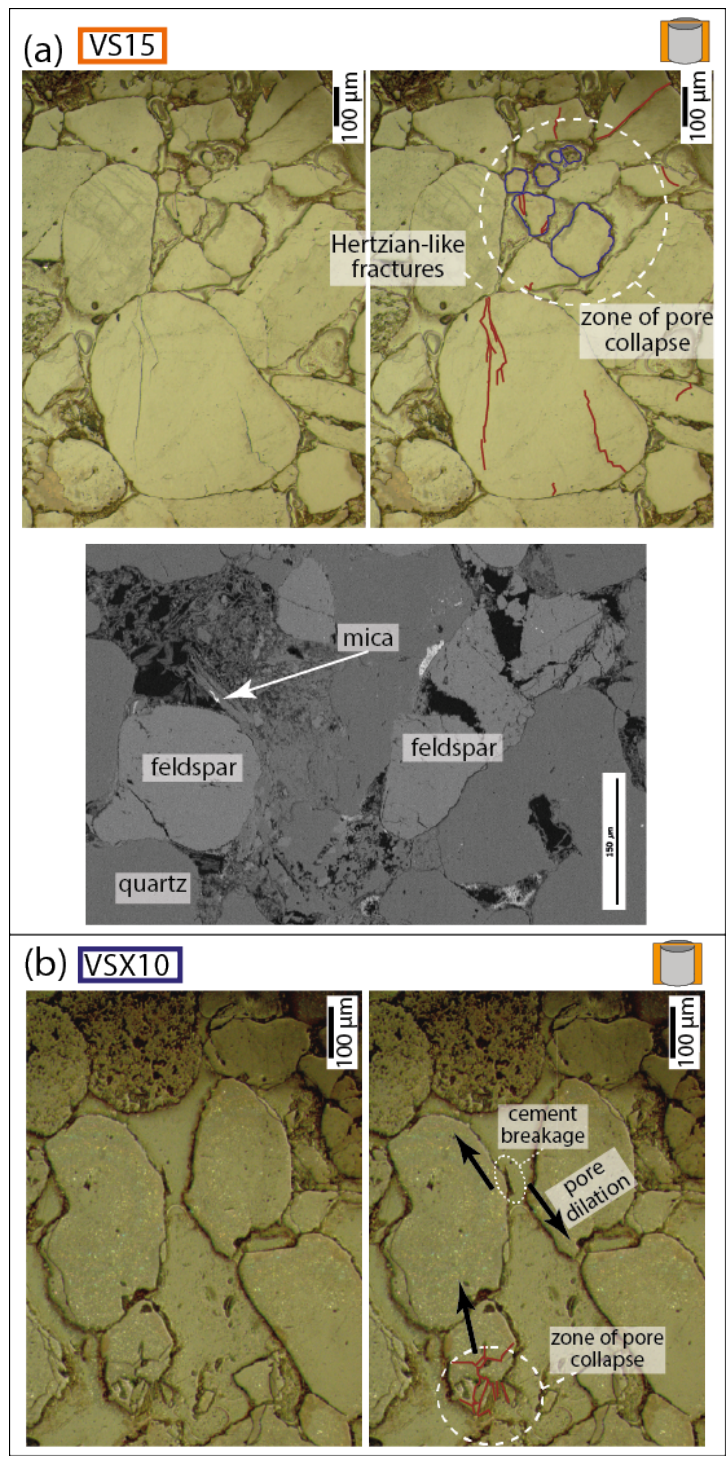

Figure 5: (a) Examples of intergranular deformation. Top: pristine and interpreted microphotograph of Hertzian-like fractures in large quartz grains and pore collapse by grain shattering. Bottom: SEM image taken in a compaction band showing a collapsed feldspar grain and deformed mica grain. (b) Intragranular deformation evidenced by fragments of cement on one of the grains and Hertzian fracturing of a grain. The bottom picture shows the interpretation, including the direction of movement of the grains. Note that Hertzian fracturing occurred before intragranular fracturing. 


\section{Discussion}

\subsection{Micromechanical damage models}

Three damage types are observed: 1) compaction bands that are formed due to grain breakage and pore collapse, mostly in feldspar and mica grains when the samples are loaded bedding perpendicular; 2) intra- or trans-granular fracturing in clusters with the largest quartz grains; 3) intergranular dilatational fracturing, that is hardly seen in dry deformed samples but that is more abundant in water-saturated samples. The presence of compaction bands is remarkable since these typically do not form in quasi-static experiments at low confining stress in sandstone [23]. Quasi-static loading data on Rothbach sandstone in P-Q space (mean stress-differential stress) defines a 'cap'-region where yielding results in the formation of shear- and compaction bands (Figure 60 25]. It becomes apparent that the dynamic loading conditions do not reach the yield cap for compaction (Figure 6, red loading path).

Two micromechanical models are considered to explain the observed microstructures, especially the compaction bands. The Hertzian contact model [34] describes intra- and trans-granular fracturing in quartz and feldspar. Intragranular fracturing is assumed to be the cause for pore collapse and subsequently the formation of compaction bands. The pore-emanated crack model [35] has been developed for intergranular fracturing. First, both models are introduced and applied for quasi-static loading conditions. After, the models are adapted for dynamic loading conditions. We argue that competition between the micromechanal models is influenced by loading rate, by the presence of pore fluids, and by microstructural properties of the rock.

The pore-emanated crack model considers circular pores in a $2 \mathrm{D}$ elastic medium. Under axial stress, mode I wing cracks emanate from the pores parallel with the loading direction. The mode I stress intensity factor $\left(K_{I}\right)$ for a single fracture evolves as follows with increasing stress [35]:

$$
K_{I}=\sqrt{L} \sigma_{1} \sqrt{\pi a}\left[\frac{1.1(1-2.1 \lambda)}{(1+L)^{3.3}}-\lambda\right]
$$




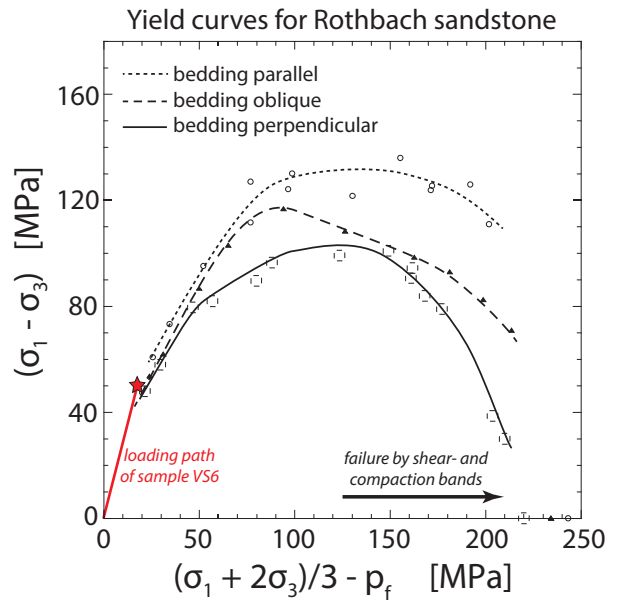

Figure 6: Mean stress-differential stress diagram for Rothbach sandstone, tested at quasistatic loading conditions for different bedding orientations by [25]. At higher mean stress the samples yield by shear bands (higher differential stress) and compaction bands (lower differential stress). At lower mean stress samples fail by classic brittle failure. The loading path for sample VS6 (red line, red star) illustrates that the dynamically loaded samples in this study do not reach conditions for shear- and compaction band formation. Nonetheless, compaction bands did form. Figure adapted from [25]. 
where $L$ is the normalized crack length $(l / a, l$ is the crack length, $a$ is the pore radius), $\sigma_{1}$ is the largest principal stress, and $\lambda=\sigma_{3} / \sigma_{1}$ ( $\sigma_{3}$ is the smallest principal stress). Compression is taken as positive. The elastic interactions between pores adds another component to the stress intensity factor [35]. Assuming $\lambda \ll 1$ for the experiments (no confining pressure), equation 1 then becomes:

$$
K_{I}=\sigma_{1} \sqrt{\pi a}\left[\frac{1.1 \sqrt{L}}{(1+L)^{3.3}}+\frac{\sqrt{2}}{\pi} \sqrt{\Phi(L+1)}\right]
$$

where $\Phi$ is the porosity. When $K_{I}$ is equal to the fracture toughness $\left(K_{I C}\right)$, stable crack growth commences. Instable crack growth occurs when the cracks have reached a critical length $L_{c r}$, which normally results in macroscopic failure of the sample by the coalescence of cracks. The peak stress at this critical crack length is the macroscopic uniaxial compressive strength $\left(\sigma_{1}=\sigma_{U C S}\right)$. Here, the analytical estimate of the formula above is adopted from [36, which involves known bulk quantities (pore size and porosity):

$$
\sigma_{U C S}=\frac{1.325}{\Phi^{0.414}} \frac{K_{I C}}{\sqrt{\pi a}}
$$

The Hertzian fracture model involves the stress concentration at a Hertzian contact point between two spherical grains. This produces tensile stress on micro flaws within the grains, leading to intragranular fracturing. The far field stress $\left(\sigma_{1}\right)$ necessary for the failure of a grain can be predicted by [34]:

$$
\sigma_{1}=\frac{2.2}{E^{2}} \frac{\left(1-\mu^{2}\right)^{2}}{(1-2 \mu)^{3}} \frac{\left(K_{I C}^{g}\right)^{3}}{(\alpha \Phi d)^{3 / 2}}
$$

where $E$ is Young's modulus, $\mu$ is the Poisson's ratio, $K_{I C}^{g}$ is the fracture toughness of the grain material, $d$ is the grain radius, $\alpha$ is the ratio between the initial micro flaw size, and $d$ is the grain radius. Note that the stress needed to break a single grain is not necessarily similar to the peak strength of the rock, but indicates the onset of pore collapse.

To obtain approximations for the uniaxial peak strength of Rothbach sandstone at quasi-static loading conditions, the following values were adopted: $\Phi=0.20$ and intergranular $K_{I C}=27 \mathrm{MPa} \mathrm{m}^{1 / 2}$. Since feldspar is elastically highly anisotropic [37] and much harder to describe by a single parameter, only 
quartz is considered here. For quartz, $E=95.4 \mathrm{GPa}$ 38, $\mu=0.077$ [34, and $K_{I C}^{g}=31 \mathrm{MPa} \mathrm{m}^{1 / 2}$. The ratio $\alpha$ varies between $1.7 \times 10^{-4}$ and $3.6 \times 10^{-5}$, where the largest value indicates larger flaws (e.g. to represent cleavage of feldspars) and the smallest one indicates very small flaws (e.g. pristine quartz) 34]. This leaves the pore and grain radii ( $a$ and $d$, respectively) as variables.

The uniaxial compressive strength (UCS) of bedding-parallel loaded sandstone predicted by the pore-emanated crack model is in good agreement with reported UCS-values 33(Figure 7a): the rock is expected to develop intergranular fractures from the largest pore sizes that were constrained from the undamaged rock (Figure 1 b, c). Also, intra-granular fracturing is only expected to occur in the largest grains, assuming a value of $\alpha$ of $1 \times 10^{-4}$ or higher (Figure 7 a). The value of $\alpha$ of $1.7 \times 10^{-4}$, representative for weaker feldspar grains, is not considered for larger grain sizes because feldspar grains in the rock are generally small.

However, pore collapse and intra-granular fracturing during dynamic loading has been observed but not explained by the quasi-static micromechanical models. Also, higher peak stresses than expected for quasi-static loading were reached during dynamic loading on dry samples. Therefore, it is necessary to incorporate the dynamic effect into the micro mechanical models, originally developed for quasi-static loading conditions.

For high strain rates it has been shown that the fracture initiation toughness exceeds the quasi-static initiation toughness of the material due to timedependent processes near the fracture tips 39, 40. Thus, a material can experience higher stresses before failure. To express this dynamic effect, an empirical function of the dynamic fracture initiation toughness $\left(K_{I C}^{D}\right)$ has been obtained from experimental high strain rate loading data of several materials that collapsed onto a single curve by the following normalization [41]:

$$
K_{I C}^{D}=K_{I C}+\dot{K} \times 2 \times 10^{-5}
$$

where $\dot{K}$ is the stress intensity factor rate and the constant with which it is multiplied is in seconds and qualitatively represent the competition between 

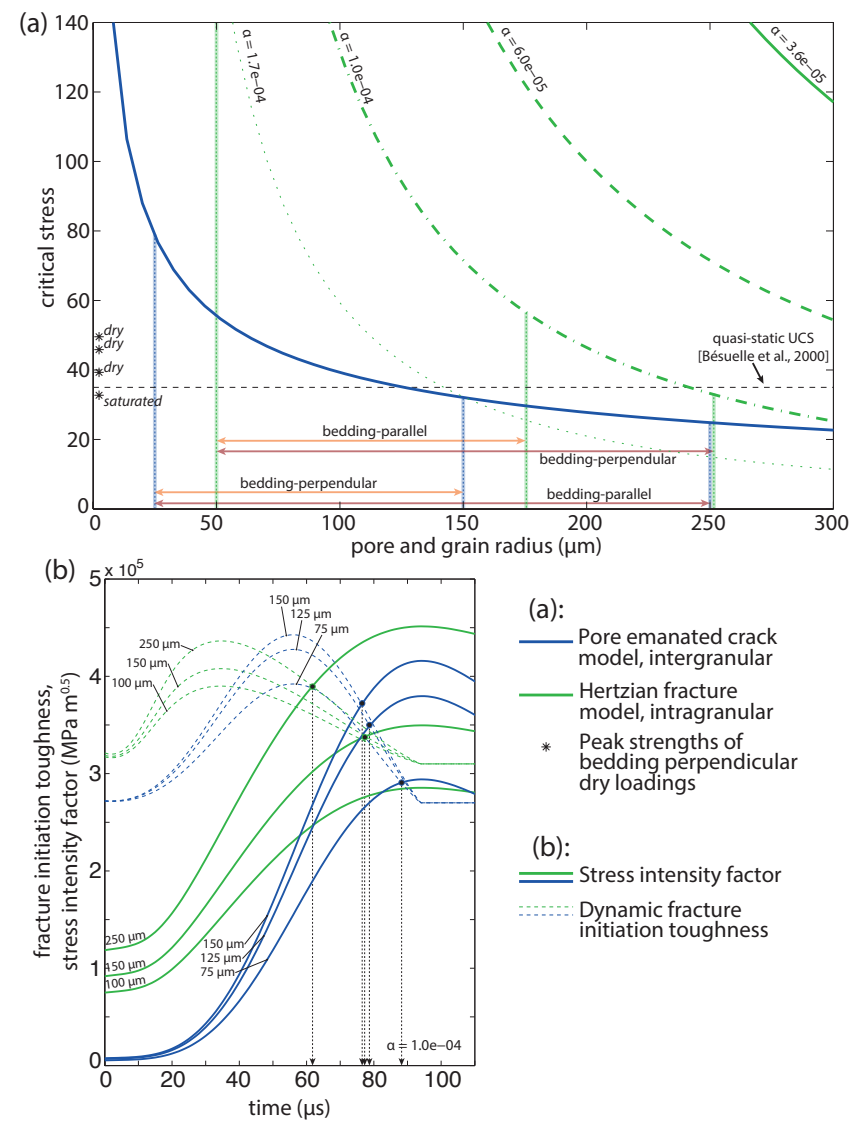

Figure 7: (a) Critical stress or peak stress for quasi-static loading of Rothbach sandstone predicted by the pore emanated crack model (blue curve) and the Hertzian fracture model (green curves) as function of pore size and grain size. For the Hertzian fracture model, four different values of $\alpha$ (ratio between the initial micro flaw size and grain radius $d$ ) are shown. The quasi-static UCS (uniaxial compressive strength) is indicated by the dashed line 33. The bedding-parallel (orange) and bedding-perpendicular (red) pore and grain size ranges for Rothbach sandstones (Figure 1) are given as well. This shows that the pore-emanated crack model determines the quasi-static strength. The asterisks indicate the dynamic peak strengths achieved during loading of samples VS6, VS15 and VS16 (dry) and VS11 (saturated). (b) The evolution of the dynamic stress intensity factor (solid curves) and the dynamic fracture initiation toughness (dashed curves) with time for the pore emanated crack model (blue) and Hertzian fracture model (green). The stress history of loading VS6 has been used as input. Curves for pores radii of 75,125 and $150 \mu \mathrm{m}$ are shown for the pore emanated crack model. Grain radii for the Hertzian fracture model are 100, 150 and $250 \mu \mathrm{m}$. Black circles indicate the moment at which the fracture criteria are satisfied. 
fracture activation time and loading rate. For low loading rates, $K_{I C}^{D}$ is equal to $K_{I C}$. Note that equation 5 does not describe the intrinsic micro strength, but does predict the increase of strength well enough so that it matches with experimental data.

For the pore-emanated crack model, the stress intensity factor is linearly proportional to the applied axial stress (equations 1 - 3). Thus, the dynamic fracture initiation toughness is proportional to the loading rate. In case of the Hertzian fracture model, the stress intensity factor is proportional to the cubed root of the applied stress (equation 4. Consequently, the dynamic fracture initiation toughness is proportional to the cubed root of the loading rate.

This different dependence on the loading rate explains why intragranular fracturing, and subsequently the formation of compaction bands, is observed in dynamic bedding-perpendicular loading. When equations 3,4 and 5 are applied to the loading history of one of the experiments, it reveals the moment at which the fracture criterion of each micromechanical model is satisfied (Figure $7 \mathrm{p}$ ). This shows that during dynamic loading, the fracture criterion for Hertzian fracturing in larger grains is satisfied early on in the loading history. When considering that feldspar grains, when oriented well, are even weaker than the parameters used here, so they break early as well (despite the smaller grain size of feldspar). This matches well with the observation of compaction band formation in relatively feldspar rich layers. Pore emanated fracturing sets in at a later moment than intragranular fracturing.

Thus, the presence of the two different deformation mechanisms reflected in the microstructural observations is due to differences in response time of these mechanisms, so that they compete at high strain rate while they would not at quasi-static strain rates. Differences in response times for deformation mechanisms in dynamically loaded rocks were suggested by [42, although micromechanical and microstructural arguments were not provided. It should also be noted that other deformation mechanisms, such as grain sliding and rotation and deformation of mica and other weak minerals, play a role as well but are not considered in the mechanical models. 


\subsection{Effect of pore fluids on dynamic damage}

The macroscopic failure mode is similar in both dry and wet cases of beddingperpendicular loading: from intact samples to fragmented samples containing compaction bands. However, in the saturated samples the deformation is more efficient (Figure 2 ), compaction band formation is less pronounced and there is some intergranular dilation.

Pore fluids in quasi-static rock deformation experiments have a weakening effect that is attributed to a drop in the specific surface energy compared to vacuum [43, 44. Water lowers the energy needed to create new fracture surface. This effect is only valid when the fracture tip speed, the speed at which fractures grow, allows for fluids to flow into the newly created fracture volume. However, much higher fracture tip speeds are expected during dynamic loading: a transgranular fracture in larger grain of $300 \mu \mathrm{m}$ is formed during a loading lasting $\sim 100 \mu \mathrm{s}$, resulting in an average velocity of $3 \mathrm{~m} / \mathrm{s}$. This number is a lower bound, but still too high to expect fluids to flow into the fracture tip zone.

Instead, we propose that the mechanical effect of the pore fluid is responsible for weakening of the rock. At the onset of loading, the fluid pressure is equal to the atmospheric pressure. It can be argued that the sample is in an undrained state during loading, meaning that the fluid pressure $\left(P_{f}\right)$ cannot be dissipated fast enough and rises with increasing stress [45]:

$$
\Delta P_{f}=B \Delta \sigma\left(\frac{1}{3}\right)
$$

where $B$ is Skempton's coefficient, which varies between 0 and 1 . This poroelastic constant can be determined for quasi-static loading by measuring axial and radial strain of the rock in both dry and saturated conditions. With our current experimental setup these were not measured. Besides, such measurement could be complicated for high strain rate loading due to radial inertia effects. An alternative could be to develop a system to measure pore fluid pressure directly during loading.

Nonetheless, this additional fluid pressure contributes to the stress intensity factor of pore-emanated cracks (equation 3), increasing the effective stress and 
lowering the critical applied stress needed to commence intergranular fracturing. This explains the suppression of compaction band formation in saturated samples and larger intergranular dilation.

\subsection{Anisotropy effect on damage mechanism}

The role of bedding orientation on the strength of the rock is large (Figure 2), as the effect of pore fluids is suppressed for bedding parallel loaded samples compared to bedding perpendicular ones. This indicates that the anisotropy, mainly caused by grain orientation, dictates the strength of the rock. This anisotropy has an effect on both micromechanical models. In case of the Hertzian fracture model, the range of grain size radii is smaller in this orientation. Hence the critical stress for intragranular fractures increases (Figure $7 \mathrm{a}$ ). The range of pore sizes is larger and therefore the critical stress for pore emanated cracks is reduced (Figure 7 a). Therefore, in contrast to bedding perpendicular loading, there is no competition between the two deformation mechanisms and intergranular fracturing is the dominant mechanism for bedding parallel loading.

\subsection{Dissipated energy and deformation mechanism}

The dissipated energy density shows that less energy is needed for the deformation of samples that are dominated by pore-emanated crack formation, such as the bedding parallel loaded samples and the fluid saturated samples (Figure 25). This is because of two reasons: 1) it costs less energy to produce new fractures between the grains than in the grains, since the grain boundaries are already weak interfaces; 2) for the pore-emanated crack model, the smallest length scale at which energy is dissipated is the grain scale. Intragranular fracturing, however, dissipates energy at a length scale below the grain scale. Therefore, energy can be dissipated at a much smaller scale, resulting in a higher dissipated energy density. In order to produce the same amount of deformation at the sample scale a much larger amount of energy is therefore needed relative to intergranular fracturing. 


\subsection{Dynamic damage across bimaterial fault zones}

The presented experiments are similar in terms of strain rate (up to $150 \mathrm{~s}^{-1}$ ) and loading duration to experiments performed on crystalline rocks [3, 4, 20, 21]. Only peak strengths have been lower, which is a consequence of the difference in strength between sandstones and granites. For crystalline rock, these loading conditions are near or at the pulverization strain rate threshold for unconfined single loading experiments. These pulverized crystalline rocks are pervasively fragmented down to micron scale or even lower [46, 21.

By contrast, sandstone at the same loading conditions remains either intact or is reduced to its individual grains. For the latter case, the smallest scale of pervasive damage is the grain scale because of intergranular dominated deformation. Therefore, we conclude that these samples cannot be labeled as pulverized since most of the smallest fragment sizes are equal to the grain size. To actually pulverize sandstones below the scale of individual grains, intragranular fracturing needs to dominate all over the sample. For the samples with compaction band formation, intragranular fracturing was only restricted to local zones with more weaker feldspar grains. We propose that higher strain rates are necessary for pervasive intragranular fracturing, and sandstone pulverization, than the ones applied in this study.

For crystalline rock, successive loadings below the pulverization strain rate threshold result in eventual pulverization of the rock [19, 21]. To pulverize sandstone by successive loadings, such loadings need to be sufficiently strong to cause energy dissipation below the grain scale. Therefore, it can be argued that successive coseismic loadings must be higher than for crystalline rock. Besides, the formation of compaction bands cause a stronger anisotropy in the rock so that progressive damage is concentrated within these compaction bands, possibly shearing these bands.

The dynamically induced microstructures that are observed in the Rothbach sandstone are not exclusive for high strain rate. Compaction bands, inter- and intra-granular breakage are commonly observed in natural sandstone that is not exposed to large earthquakes. Also, several experimental studies have been able 
to create such microstructures in Rothbach sandstone during quasi-static experiments 25. However, such quasi-statically formed compaction bands do necessitate high confining pressure. Thus, dynamically formed compaction bands can easily be mistaken for quasi-static ones and vice versa without proper geological constraints on the depth of formation.

In the setting of a seismically active fault zone, transient coseismic loading is the result of the stress waves radiating from a passing earthquake rupture tip. The loading conditions, mainly strain rate, can be calculated for simple rupture mechanisms (e.g. sub-Rayleigh wave speed rupture at constant velocity, supershear rupture). Here, we adapt a simple conceptual model where there is no preferred earthquake rupture directionality along a bimaterial fault. This causes systematic compressional loading with similar transient strain rates on both sides of the fault (Figure 8 a).

For the crystalline lithology, the transient coseismic loading results in a wide damage zone that is clearly defined by an increasing density of fractures towards the fault core (Figure 8b, 21]). Even more, a band of pulverized rock forms close to the fault core when loading conditions are sufficiently high (Figure 8b, [21]). On the other side of the fault with the porous lithology, pervasive pulverization below the grain scale occurs at higher strain rates, resulting in an asymmetric distribution of pulverized rocks (Figure 8p). Moreover, damage in the porous rock farther from the fault core (where strain rates are lower) is harder to recognize because energy is dissipated mostly at the grain scale, causing intergranular deformation, and because the microstructures such as compaction bands are not unique for dynamic loading.

The different mechanical response of porous rock and crystalline rock to similar transient loading conditions can explain the subsurface damage asymmetry across fault zones as observed by [2, 14] and [8]. However, it should be noted that the rupture mechanism and preferred rupture directivity is governed at seismogenic depth. Thus, the assumption of perfectly bidirectional ruptures causing similar transient loading conditions can differ from reality. Our findings therefore do not exclude the possibility of a preferred rupture direction. Nonetheless, 
457

one should use caution when assessing fault damage zone asymmetry across a bimaterial fault by taking the different dynamic mechanical response into account. Also, sub-surface damage asymmetry as a stand-alone observation might not be sufficient to constrain a preferential rupture mode or direction. In such a case, the support from other geophysical observations, such as an elastic velocity contrast at depth, is vital.

Besides, the hypothesis of a preferred rupture direction as the cause for the asymmetric damage distribution across a fault zone assumes that the stiffer crystalline side of the fault is subject to systematic tensile loading [16]. This implies that tensile loading causes pulverization rather than compressive loading. The current state of experimental research on pulverized rocks has not yet considered dynamic tensile loading, and therefore this remains an open question for now. 


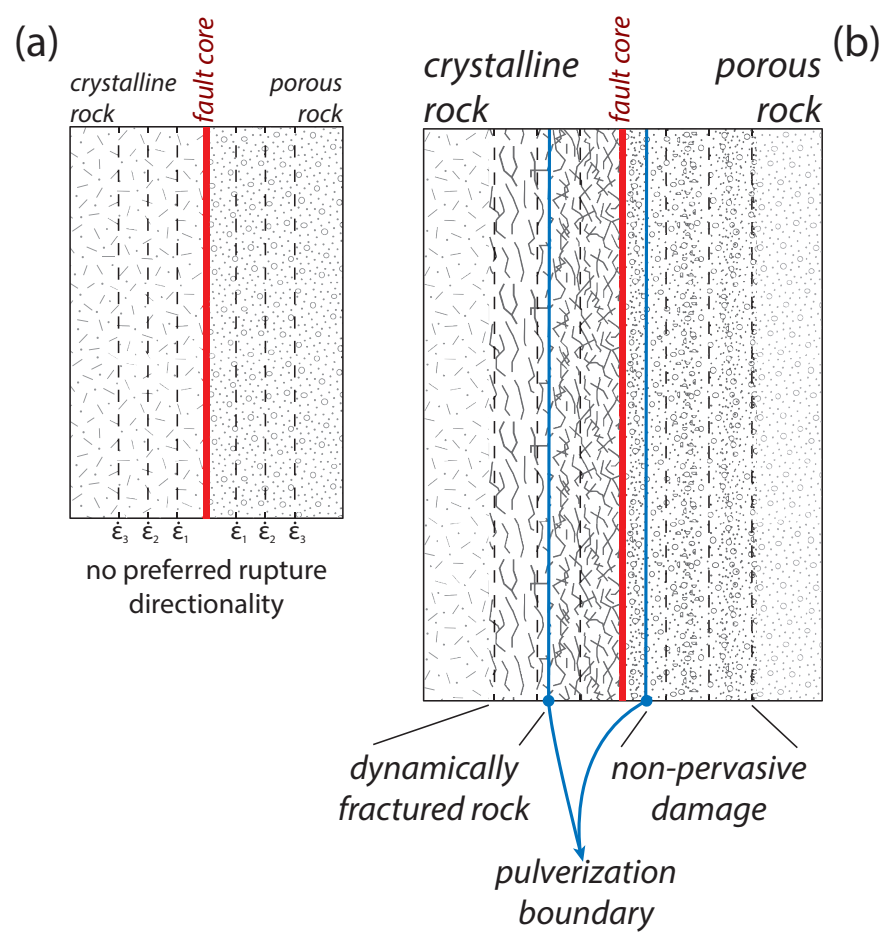

Figure 8: (a) Top view of a simple conceptual model of the fault damage zone geometry across a bimaterial fault consisting of crystalline rocks on the left side and porous rock on the right side. The strain rate contours are the representation of the same strain rate pattern on both sides of the fault caused by several identical earthquake ruptures travelling in opposite directions. The dimensions of the system depend on the size of the earthquakes and the rupture mode. (b) The different response of the lithologies causes an asymmetric distribution of pulverized rock across the fault. Also, damage in porous rock farther from the fault core is harder to recognize because it is intergranular and can be confused for quasi-statically induced damage. 


\section{Conclusion}

High strain rate deformation experiments on Rothbach sandstone were performed to study dynamic coseismic damage in porous rock. The results show that for the investigated strain rate range $\left(60-150 \mathrm{~s}^{-1}\right)$ the strength and the damage microstructures depend on the loading direction with respect to the sedimentary bedding and, in a lesser extent, on the presence of pore fluids. Pervasive fracturing below the grain scale, what could be called pulverization, has not been observed. Instead, energy was dissipated at the grain scale, i.e. intergranular deformation, and locally below the grain scale in the form of intragranular fractures and compaction bands. The competition between these two mechanisms is explained by using the geometrical properties of the rock, that differ with the orientation relative to the bedding, in combination with two classic micromechanical models by $[35,34]$. This analysis shows that the inertiarelated response time for intergranular breakage is shorter than for intragranular breakage, suggesting that pervasive fracturing below the grain scale might occur at even higher strain rates than the ones used here. Straightforward comparison with crystalline rocks tested at similar high strain rate loading conditions reveals that damage zone asymmetry across bimaterial fault zones can be caused by a different response in terms of damage. Moreover, the microstructures observed in the porous rock are not exclusive indicators for high strain rate loadings. Therefore, caution should be used when assessing the origin of off-fault damage in porous rock.

\section{Acknowledgments}

FA and MLD have performed the experiments and processed the data. All four authors have contributed to the discussion and the final version of the manuscript. The project has received funding from the European Union's Seventh Framework Programme for research, technological development and demonstration under grant agreement no 316889 (ITN FlowTrans). Funding 
from Labex OSUG@2020 (Investissement d'avenir-ANR10-LABX56) is acknowledged. Joséphine Gervin is acknowledged for the development of the data acquisition system on the SHPB. We thank Anne-Marie Boullier for discussion.

\section{References}

[1] O. Dor, Y. Ben-Zion, T. Rockwell, J. Brune, Pulverized rocks in the Mojave section of the San Andreas Fault Zone, Earth and Planetary Science Letters 245 (3-4) (2006) 642-654. doi:10.1016/j.epsl.2006.03.034.

[2] O. Dor, T. Rockwell, Y. Ben-Zion, Geological Observations of Damage Asymmetry in the Structure of the San Jacinto, San Andreas and Punchbowl Faults in Southern California: A Possible Indicator for Preferred Rupture Propagation Direction, Pure and Applied Geophysics 163 (2006) 301349. doi:10.1007/s00024-005-0023-9.

[3] M.-L. Doan, G. Gary, Rock pulverization at high strain rate near the San Andreas fault, Nature Geoscience 2 (10) (2009) 709-712. doi:10.1038/ ngeo640

[4] F. Yuan, V. Prakash, T. Tullis, Origin of pulverized rocks during earthquake fault rupture, Journal of Geophysical Research 116 (B6) (2011) B06309. doi:10.1029/2010JB007721.

[5] C. Rowe, W. Griffith, Do Faults Preserve a Record of Seismic Slip: A second opinion, Journal of Structural Geology 78. doi:10.1016/j.jsg. 2015.06 .006

[6] F. Aben, M.-L. Doan, J.-P. Gratier, F. Renard, Coseismic damage generation and pulverization in fault zones: insights from dynamic SplitHopkinson Pressure Bar experiments, in: M. Thomas, H. Bhat, T. Mitchell (Eds.), Evolution of Fault Zone Properties and Dynamic Processes during Seismic Rupture. 
[7] T. Rockwell, M. Sisk, G. Girty, O. Dor, N. Wechsler, Y. Ben-Zion, Chemical and physical characteristics of pulverized tejon lookout granite adjacent to the San Andreas and garlock faults: Implications for earthquake physics, Pure and Applied Geophysics 166 (10-11) (2009) 1725-1746. doi:10.1007/ s00024-009-0514-1.

[8] T. Mitchell, Y. Ben-Zion, T. Shimamoto, Pulverized fault rocks and damage asymmetry along the Arima-Takatsuki Tectonic Line, Japan, Earth and Planetary Science Letters 308 (3-4) (2011) 284-297. doi:10.1016/j.epsl. 2011.04 .023

[9] F. Agosta, A. Aydin, Architecture and deformation mechanism of a basinbounding normal fault in Mesozoic platform carbonates, central Italy, Journal of Structural Geology 28 (8) (2006) 1445-1467. doi:10.1016/j.jsg. 2006.04 .006

[10] A. Sagy, D. Korngreen, Dynamic branched fractures in pulverized rocks from a deep borehole, Geology 40 (9) (2012) 799-802. doi:10.1130/ G33194.1.

[11] M. Fondriest, S. Aretusini, G. Di Toro, S. Smith, Fracturing and rock pulverization along an exhumed seismogenic fault zone in dolostones: The Foiana Fault Zone (Southern Alps, Italy), Tectonophysicsdoi:10.1016/j. tecto.2015.04.015

[12] O. Dor, J. Chester, Y. Ben-Zion, J. Brune, T. Rockwell, Characterization of Damage in Sandstones along the Mojave Section of the San Andreas Fault: Implications for the Shallow Extent of Damage Generation, Applied Geophysics 166 (2009) 1747-1773. doi:10.1007/s00024-009-0516-z.

[13] W. Key, R. Schultz, Fault formation in porous sedimentary rocks at high strain rates: First results from the Upheaval Dome impact structure, Utah, USA, Geological Society of America Bulletin 123 (5-6) (2011) 1161-1170. doi:10.1130/B30087.1. 
[14] O. Dor, C. Yildirim, T. Rockwell, Y. Ben-Zion, Ö. Emre, M. Sisk, T. Duman, Geological and geomorphologic asymmetry across the rupture zones of the 1943 and 1944 earthquakes on the North Anatolian Fault: possible signals for preferred earthquake propagation direction, Geophysical Journal International 173 (2) (2008) 483-504. doi:10.1111/j.1365-246X.2008. 03709.x

[15] J. Weertman, Unstable slippage across a fault that separates elastic media of different elastic constants, Journal of Geophysical Research 85 (B3) (1980) 1455-1461. doi:doi:10.1029/JB085iB03p01455

[16] Y. Ben-Zion, Z. Shi, Dynamic rupture on a material interface with spontaneous generation of plastic strain in the bulk, Earth and Planetary Science Letters 236 (1-2) (2005) 486-496. doi:10.1016/j.epsl.2005.03.025

[17] Z. Shi, Y. Ben-zion, Dynamic rupture on a bimaterial interface governed by slip-weakening friction, Geophysical Journal International 165 (2) (2006) 469-484. doi:10.1111/j.1365-246X.2006.02853.x.

[18] K. Xia, M. Nasseri, B. Mohanty, F. Lu, R. Chen, S. Luo, Effects of microstructures on dynamic compression of Barre granite, International Journal of Rock Mechanics and Mining Sciences 45 (2008) 879-887. doi: 10.1016/j.ijrmms.2007.09.013.

[19] M.-L. Doan, A. Billi, High strain rate damage of Carrara marble, Geophysical Research Letters 38 (19). doi:10.1029/2011GL049169.

[20] M.-L. Doan, V. D'Hour, Effect of initial damage on rock pulverization along faults, Journal of Structural Geology 45 (2012) 113-124. doi:10.1016/j. jsg.2012.05.006.

[21] F. Aben, M.-L. Doan, T. Mitchell, R. Toussaint, T. Reuschlé, M. Fondriest, J.-P. Gratier, F. Renard, Dynamic fracturing by successive coseismic loadings leads to pulverization in active fault zones, Journal of Geophysical Research: Solid Earth 121 (2016) 1-23. doi:10.1002/2015JB012542. 
[22] H. Fossen, R. A. Schultz, Z. K. Shipton, K. Mair, Deformation bands in sandstone: a review, Journal of the Geological Society 164 (4) (2007) 755769. doi:10.1144/0016-76492006-036

URL http://jgs.lyellcollection.org/content/164/4/755.short

[23] T.-F. Wong, P. Baud, The brittle-ductile transition in porous rock: A review, Journal of Structural Geology 44 (2012) 25-53. doi:10.1016/j.jsg. 2012.07 .010

[24] C. David, T.-F. Wong, W. Zhu, J. Zhang, Laboratory measurement of compaction-induced permeability change in porous rocks: Implications for the generation and maintenance of pore pressure excess in the crust, Pure and Applied Geophysics 143 (1-3) (1994) 425-456. doi:10.1007/ BF00874337.

[25] L. Louis, P. Baud, T.-F. Wong, Microstructural inhomogeneity and mechanical anisotropy associated with bedding in rothbach sandstone, Pure and Applied Geophysics 166 (2009) 1063-1087. doi:10.1007/ s00024-009-0486-1.

[26] L. Louis, T.-F. Wong, P. Baud, Imaging strain localization by X-ray radiography and digital image correlation: Deformation bands in Rothbach sandstone, Journal of Structural Geology 29 (1) (2007) 129-140. doi:10.1016/j.jsg.2006.07.015.

[27] E. Klein, T. Reuschlé, A pore crack model for the mechanical behaviour of porous granular rocks in the brittle deformation regime, International Journal of Rock Mechanics and Mining Sciences 41 (6) (2004) 975-986. doi:10.1016/j.ijrmms.2004.03.003.

[28] L. Louis, C. David, P. Robion, Comparison of the anisotropic behaviour of undeformed sandstones under dry and saturated conditions, Tectonophysics 370 (1-4) (2003) 193-212. doi:10.1016/S0040-1951(03)00186-0. 
[29] T.-F. Wong, C. David, W. Zhu, The transition from brittle faulting to cataclastic flow in porous sandstones: Mechanical deformation, Journal of Geophysical Research 102 (B2) (1997) 3027. doi:10.1029/96JB03282

[30] Q. Zhang, J. Zhao, A Review of Dynamic Experimental Techniques and Mechanical Behaviour of Rock Materials, Rock Mechanics and Rock Engineeringdoi:10.1007/s00603-013-0463-y.

[31] B. Gama, S. Lopatnikov, J. Gillespie, Hopkinson bar experimental technique: A critical review, Applied Mechanics Reviews 57 (4) (2004) 223. doi:10.1115/1.1704626.

[32] W. Chen, B. Song, Split Hopkinson (Kolsky) Bar. Design, Testing and 1 Applications, first edit Edition, Springer, New York, 2011. doi:10.1007/ 978-1-4419-7982-7.

[33] P. Bésuelle, J. Desrues, S. Raynaud, Experimental characterisation of the localisation phenomenon inside a Vosges sandstone in a triaxial cell, Rock Mechanics and Mining Sciences 37 (2000) 1223-1237.

[34] J. Zhang, T.-F. Wong, D. Davis, Micromechanics of pressure-induced grain crushing in porous rocks, Journal of Geophysical Research 95 (B1) (1990) 341. doi:10.1029/JB095iB01p00341.

[35] C. Sammis, M. Ashby, The failure of brittle porous solids under compressive stress states, Acta Metallurgica 34 (3) (1986) 511-526. doi: 10.1016/0001-6160(86)90087-8.

[36] W. Zhu, P. Baud, T.-F. Wong, Micromechanics of cataclastic pore collapse in limestone, Journal of Geophysical Research: Solid Earth 115 (4). doi: 10.1029/2009JB006610.

[37] J. Brown, R. Angel, N. Ross, Elasticity of plagioclase feldspars, Journal of Geophysical Research B: Solid Earth 121 (2) (2016) 663-675. doi:10. 1002/2015JB012736 
[38] W. Pabst, E. Gregorová, Elastic properties of silica polymorphs - A review Ceramics-Silikáty 57 (3) (2013) 167-184. URL http://www.ceramics-silikaty.cz/2013/2013\{_\}03\{_\}167.htm

[39] K. Ravi-Chandar, W. Knauss, An experimental investigation into dynamic fracture: I. Crack initiation and arrest, International Journal of Fracture 25 (4) (1984) 247-262. doi:10.1007/BF00963460

[40] C. Liu, W. Knauss, A. Rosakis, Loading rates and the dynamic initiation toughness in brittle solids, International Journal of Fracture 90 (1998) 103118.

[41] H. Bhat, A. Rosakis, C. Sammis, A Micromechanics Based Constitutive Model for Brittle Failure at High Strain Rates, Journal of Applied Mechanics 79 (2012) 031016.1 - 031016.12. doi:10.1115/1.4005897.

[42] A. Fossum, R. Brannon, On a viscoplastic model for rocks with mechanismdependent characteristic times, Acta Geotechnica 1 (2006) 89-106. doi: $10.1007 / \mathrm{s} 11440-006-0010-\mathrm{z}$

[43] P. Baud, W. Zhu, T.-F. Wong, Failure mode and weaking effect of water on sandstone, Journal of Geophysical Research 105 (B7) (2000) 16371-16389.

[44] P. Baud, T. Reuschlé, Y. Ji, C. Cheung, T.-F. Wong, Mechanical compaction and strain localization in Bleurswiller sandstone, Journal of Geophysical Research: Solid Earth 120. doi:10.1002/2015JB012192. Received.

[45] Y. Guéguen, V. Palciauskas, Introduction to the physics of rock, Princeton University Press, New Jersey, 1994.

[46] J. Muto, T. Nakatani, O. Nishikawa, H. Nagahama, Fractal particle size distribution of pulverized fault rocks as a function of distance from the fault core, Geophysical Research Letters (2015) 1-9.doi:10.1002/ 2015GL064026. Received. 